\title{
Use of spirometry and respiratory drugs in Manitobans over 35 years of age with obstructive lung diseases
}

\author{
NR Anthonisen $M D^{1}$, K Wooldrage $B S{ }^{1}$, J Manfreda $M D^{1,2}$
}

\begin{abstract}
NR Anthonisen, K Wooldrage, J Manfreda. Use of spirometry and respiratory drugs in Manitobans over 35 years of age with obstructive lung diseases. Can Respir J 2005;12(2):69-74.
\end{abstract}

BACKGROUND: Previous data indicated that spirometry was underused in people with obstructive disease, especially those with chronic obstructive pulmonary disease (COPD).

OBJECTIVE: To examine the use of respiratory drugs in patients with COPD and asthma, and to relate drug use to spirometry.

METHODS: Manitoba Health maintains a database of physician services remunerated by fees that includes spirometry. The database contains the diagnosis and patient identifiers, as well as sex, date of birth and residential postal code. Similar identifiers are used in the provincial pharmacare program that records prescriptions dispensed at retail pharmacies. These databases were examined for the time period between 1996 to 2000, and people over 35 years of age diagnosed with asthma, COPD or both were identified. The frequency of spirometry in these patients and their use of respiratory drugs was determined.

RESULTS: Spirometry and drug prescription frequencies increased with the number of physician visits (including those for bronchitis), but their patterns differed. Patients with asthma or asthma plus COPD had considerably higher rates of drug prescription and slightly higher spirometry rates than did those with COPD. Patients with asthma and asthma plus COPD who underwent spirometry were slightly more likely to receive drugs than those who did not undergo spirometry; this trend was more striking in patients with COPD. However, approximately $30 \%$ of patients with COPD who had five physician visits and who underwent spirometry did not receive drugs; this was true for approximately $10 \%$ of similar patients with asthma. Patients with asthma generally received beta-agonists and inhaled steroids; these agents were less commonly given to patients with COPD, who instead were given anticholinergics much more often than were asthmatics. Patients who were diagnosed with asthma plus COPD had beta-agonist and inhaled corticosteroid prescription rates similar to asthmatics, and anticholinergic prescription rates similar to patients with COPD. Theophylline and antileukotriene drugs were used less often than were inhaled agents. In patients with asthma, drugs were frequently discontinued, and during drug use, prescription refills were consistent with an intake of $30.9 \%$ of the prescribed doses. In patients with COPD, discontinuing drugs early was uncommon, and refills were consistent with the use of $54 \%$ of the prescribed amounts. The same was true of patients with both COPD and asthma.

DISCUSSION: Drug prescription was considerably more common in patients labelled with asthma or COPD plus asthma than in patients with COPD. Spirometry was also less common in patients with COPD but had a distinct influence on the frequency of drug prescription. Patterns of drug prescription were predictable, and patterns of drug use indicated poor compliance, in agreement with other data.
The results suggest that COPD symptoms may be discounted and patients systematically undertreated or the diagnosis could frequently be applied to people with trivial disease or both.

Key Words: Asthma; COPD; Inhaled bronchodilators; Inhaled corticosteroids

\section{Spirométrie et pharmacothérapie respiratoire chez les Manitobains de plus de 35 ans atteints de maladie pulmonaire obstructive}

HISTORIQUE : Des données antérieures indiquaient que la spirométrie était sous-utilisée chez les personnes atteintes de maladie obstructive, surtout en présence de MPOC (maladie pulmonaire obstructive chronique).

OBJECTIF : Vérifier l'utilisation de la pharmacothérapie respiratoire chez les patients atteints de MPOC et d'asthme et établir le rapport entre pharmacothérapie et spirométrie.

MÉTHODE : Le ministère de la santé du Manitoba maintient une base de données sur les services de santé rémunérés, notamment la spirométrie. La base de données renferme le diagnostic et les identificateurs des patients, de même que leur sexe, leur date de naissance et leur code postal. Des identificateurs semblables sont utilisés par le programme d'assurance santé provincial qui enregistre les ordonnances servies dans les pharmacies de détail. Ces bases de données sont analysées pour la période allant de 1996 à 2000 et on a identifié les personnes de 35 ans et plus ayant un diagnostic d'asthme ou de MPOC ou les deux. La fréquence de la spirométrie chez ces patients et leur utilisation des médicaments respiratoires ont été notées.

RÉSULTATS : La fréquence de la spirométrie et des médicaments d'ordonnance a augmenté en proportion du nombre de consultations médicales (y compris pour bronchite), mais leur mode différait. Les patients souffrant d'asthme ou d'asthme plus MPOC utilisaient beaucoup plus de médicaments d'ordonnance et un peu moins de spirométrie que les patients souffrant de MPOC. Les patients souffrant d'asthme et d'asthme plus MPOC qui faisaient de la spirométrie étaient légèrement plus susceptibles de recevoir des médicaments que ceux qui ne faisaient pas de spirométrie. Cette tendance s'est révélée plus notable chez les patients atteints de MPOC. Par contre, environ $30 \%$ des patients atteints de MPOC qui avaient consulté cinq fois le médecin et qui faisaient de la spirométrie ne prenaient pas de médicaments. Cela était vrai d'environ $10 \%$ des patients asthmatiques présentant les mêmes caractéristiques. Les patients asthmatiques recevaient en général des bêta-agonistes et des corticostéroïdes par inhalation. Ces agents étaient moins souvent administrés aux patients atteints de MPOC qui recevaient davantage d'anticholinergiques comparativement aux asthmatiques. Les patients ayant un diagnostic d'asthme plus MPOC prenaient autant de bêtaagonistes et de corticostéroïdes par inhalation que les asthmatiques et les taux d'ordonnances d'anticholinergiques étaient semblables à ceux des patients atteints de MPOC. La théophylline et les antileucotriènes ont

Departments of ${ }^{1}$ Internal Medicine and ${ }^{2}$ Community Health Sciences, University of Manitoba, Winnipeg, Manitoba

Correspondence: Dr NR Anthonisen, Respiratory Hospital, 810 Sherbrook Street, Winnipeg, Manitoba R3A 1R8. Telephone 204-787-2562,

fax 204-787-4586, e-mail nanthonisen@exchange.hsc.mb.ca 
été utilisés moins souvent que les agents par inhalation. Chez les patients asthmatiques, les médicaments étaient souvent cessés et durant leur utilisation, le renouvellement des ordonnances concordait avec la prise de $30,9 \%$ des doses prescrites. Chez les patients atteints de MPOC, l'abandon précoce des médicaments était rare et le renouvellement correspondait à l'utilisation de $54 \%$ des doses prescrites. Il en allait de même pour les patients atteints de MPOC et d'asthme.

DISCUSSION : Les ordonnances étaient beaucoup plus fréquentes chez les patients atteints d'asthme ou de MPOC plus asthme que chez les patients atteints de MPOC. La spirométrie était également plus utilisée chez les patients atteints de MPOC, mais a exercé une influence distincte sur la fréquence des ordonnances de médicaments. Les modes d'ordonnance de médicaments étaient prévisibles et les modes d'utilisation des médicaments confirmaient la piètre observance thérapeutique révélée par d'autres données. Les résultats donnent à penser que les symptômes de la MPOC pourraient être sous-estimés et que les patients pourraient être en général trop peu traités ou alors, le diagnostic serait fréquemment appliqué à des gens dont la maladie est bénigne, à moins que les deux phénomènes ne concourent.
$\mathrm{T}_{\mathrm{r}}^{\mathrm{h}} \mathrm{me}$ he use of spirometry and the measurement of forced expiratory volume in $1 \mathrm{sec}$ and forced vital capacity was recently examined in patients diagnosed with obstructive lung diseases (asthma and chronic obstructive pulmonary disease [COPD]) in Manitoba (1). There were significant diagnosisdependent differences in spirometry use: the test was performed more often in patients labelled with asthma. This suggested that the management of patients labelled with COPD was less compliant with guidelines (2-4), which recommend routine spirometry. We further explored this issue by examining drug use as a function of diagnosis and spirometry, with the hypothesis that spirometry use would correlate with appropriate drug prescription.

\section{METHODS}

Manitoba Health maintains a database of physician services that includes each patient's personal health insurance number, sex, date of birth and residential postal code. These can be compared with the Manitoba Population Registry, which is also maintained by Manitoba Health. Since 1995, Manitoba Health has also maintained a database of prescription records submitted by retail pharmacies that includes the drug name, date of prescription, dose and quantity dispensed. This database contains virtually all prescriptions dispensed in retail pharmacies (5), and can be linked to the physician service database and the Population Registry. After approval from the University of Manitoba's Committee on the Ethics of Human Experimentation (Winnipeg, Manitoba) and from the Access Committee of Manitoba Health (Winnipeg, Manitoba), data files were obtained with anonymous personal health insurance numbers of Manitobans who had physician services for obstructive lung diseases and those who had received drugs prescribed for these conditions.

Because of the authors' interest in COPD, the examination was confined to people older than 35 years of age in 1996. The time period from 1996 to 2000 was studied because the drug data from this time period was available and reliable.

The lung diseases studied were asthma (International Classification of Diseases, Ninth Revision [ICD-9] (6) code 493); COPD, including chronic bronchitis (ICD-9 code 491), emphysema (ICD-9 code 492) and chronic airway obstruction (ICD-9 code 496); and bronchitis, including acute bronchitis (ICD-9 code 466) and bronchitis not specified as acute or chronic (ICD-9 code 490). People with these diagnoses were enumerated, as were the number of physician claims for visits citing these diagnoses, except those for spirometry. The vast majority (86.8\%) of the people enumerated were alive and in Manitoba for the full five-year period (ie, they entered the cohort in January 1996 and exited in December 2000).

Spirometry claims were those for measurement of forced expiratory volume in $1 \mathrm{~s}$ and forced vital capacity, whether or not they also included an assessment of maximum midexpiratory flow or instantaneous flow measurements derived from the expiratory flow-volume curve. Two measurements done on the same day were treated as a single measurement.
The respiratory drugs examined were inhaled beta-agonists, including both long- and short-acting preparations; inhaled anticholinergics; inhaled corticosteroids; theophylline preparations; and leukotriene antagonists. Agents that combined beta-agonists and anticholinergics were counted as anticholinergics, and combinations of beta-agonists and corticosteroids were counted as corticosteroids. Beta-agonist steroid combination drugs were not commonly prescribed during the study period. The number of people with the diagnoses of interest who were prescribed drugs at any time during the observation period was noted. Drug-taking behaviour in patients with a diagnosis of interest who received drugs on more than one occasion was examined. From each prescription, the date and quantity of drug dispensed, and the number of days the prescription was designed to cover were obtained. From these data, the days of coverage (ie, the number of days between the first prescription and the end of the study, death or departure from the province) was computed for each participant who was given a drug for COPD or asthma. During this interval, the treatment period was identified (ie, the interval between the date of the first prescription and the date when the last prescription lapsed). During the treatment period, the number of days for which the drugs was dispensed were counted. From these data, the fraction of days that a patient apparently took the prescribed dose of the drug (\% full dose) was calculated.

The number of visits to a physician per five person-years of observation was calculated for each patient. Median values and interquartile intervals are presented for non-normally distributed variables, and nonparametric methods were used to test for statistical differences. Logistic regression was used to compare diagnostic groups with respect to drug and spirometry use (7). $\mathrm{P}<0.05$ was considered statistically significant.

\section{RESULTS}

Figure 1 shows Venn diagrams for the diagnoses of interest in men and women. Among Manitobans older than 35 years of age, $38.5 \%$ of women and $32.5 \%$ of men had one of the diagnoses of interest in 1996 to 2000 . Of these, approximately $60 \%$ of both men and women had physician claims for bronchitis only. COPD and COPD plus bronchitis were more common in men than women, while the reverse was true of asthma and asthma plus bronchitis. Approximately $4 \%$ of people with obstructive disease were labelled with all three diagnoses, and approximately $2 \%$ with asthma plus COPD. The prevalence of bronchitis and COPD increased with the age of the patient in men and women; however, for bronchitis, the effect of age was much less prominent in women than in men. There was no clear influence of age on the prevalence of asthma in either sex. COPD prevalence increased in both men and women over 75 years of age, but not in younger age groups over the five years studied. In both sexes, bronchitis and asthma prevalence increased little during the study period.

People who had physician visits for bronchitis only had relatively low rates of spirometry and drug prescription: approximately 


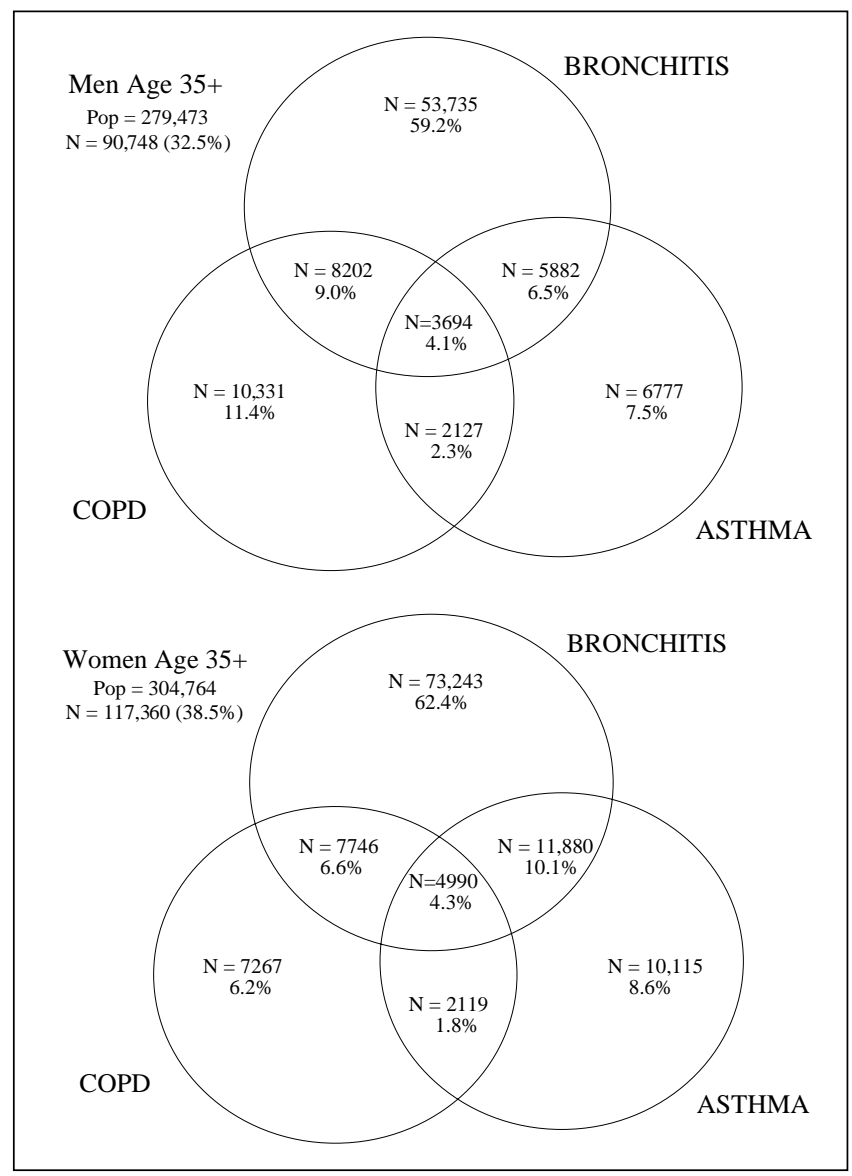

Figure 1) Venn diagrams for chronic obstructive pulmonary disease (COPD), asthma and bronchitis according to sex. Pop Population

$10 \%$ had spirometry and less than 20\% were presecribed respiratory drugs. Also, visits for bronchitis had only a marginal effect on the rates of spirometry and drug prescription in people with a diagnosis of asthma or COPD. Because of this, the results are not reported for those with a sole diagnosis of bronchitis; instead, those with the diagnoses of COPD, asthma or the combination of COPD and asthma were examined and the visits for bronchitis among these people were counted without distinguishing them from visits for asthma or COPD. This approach captured data of people who had visits for bronchitis as well as for asthma, COPD or both. There were 33,536 people with COPD, 34,654 with asthma and 12,930 with both. The distribution of patients according to physician visits for these diagnoses per five person-years for the three groups is shown in Table 1. The differences between COPD and asthma patients were relatively minor; a greater fraction of COPD patients were seen only once and a larger fraction were seen more than 20 times. Patients with the combination diagnosis differed sharply: $78.3 \%$ were seen over five times, while this was true for only $42.2 \%$ of patients with COPD and $38.4 \%$ of those with asthma who were seen at least twice for these conditions (Table 1).

The frequency of spirometry and drug prescription increased with the number of physician visits an individual made but differed with the diagnostic category. Table 2 shows the percentages of patients in each diagnostic group who had spirometry and were prescribed drugs. For the same number of
TABLE 1

Distribution of patients by the number of visits and the diagnostic group

\begin{tabular}{lcrrrrrrr}
\hline & \multicolumn{8}{c}{ Number of visits per $\mathbf{5}$ person-years* $\mathbf{( \% )}$} \\
\cline { 2 - 9 } & $\mathbf{1}$ & $\mathbf{2}$ & $\mathbf{3}$ & $\mathbf{4}$ to $\mathbf{5}$ & $\mathbf{6}$ to $\mathbf{9}$ & $\mathbf{1 0}$ to $\mathbf{1 9}$ & $\mathbf{2 2 0}$ \\
\hline Asthma $(\mathrm{n}=34,654)$ & 21.6 & 17.5 & 13.1 & 17.7 & 16.3 & 10.6 & 3.2 \\
COPD $(\mathrm{n}=33,536)$ & 24.4 & 17.0 & 12.0 & 14.7 & 13.4 & 10.3 & 8.2 \\
Asthma + COPD & - & 3.9 & 5.4 & 12.3 & 21.6 & 28.9 & 27.8 \\
$\quad(\mathrm{n}=12,930)$ & & & & & & & \\
Asthma $(\mathrm{n}=26,613)^{\dagger}$ & - & 22.3 & 16.7 & 22.6 & 20.8 & 13.5 & 4.1 \\
COPD $(\mathrm{n}=14,194)^{\dagger}$ & - & 22.5 & 15.6 & 19.5 & 17.7 & 13.6 & 10.9
\end{tabular}

*Includes visits for bronchitis; ${ }^{\dagger}$ Asthmatics and patients with chronic obstructive pulmonary disease (COPD) who had two or more visits

TABLE 2

Percentages of patients who had spirometry and were given drugs as a function of number of visits

\begin{tabular}{|c|c|c|c|c|c|c|}
\hline \multirow{2}{*}{$\begin{array}{l}\text { Visits per } \\
5 \text { person-years }{ }^{*}\end{array}$} & \multicolumn{2}{|c|}{ Asthma } & \multicolumn{2}{|c|}{ COPD } & \multicolumn{2}{|c|}{ Asthma + COPD } \\
\hline & ${ }^{*}$ Spirometr & Drugs & Spirometry & Drugs & Spirom & Drugs: \\
\hline 1 & 30 & 58 & 27 & 21 & - & - \\
\hline 2 & 37 & 73 & 33 & 33 & 48 & 68 \\
\hline 3 & 40 & 80 & 36 & 45 & 52 & 75 \\
\hline 4 to 5 & 45 & 86 & 40 & 54 & 56 & 86 \\
\hline 6 to 9 & 52 & 92 & 45 & 67 & 60 & 93 \\
\hline 10 to 19 & 61 & 97 & 50 & 83 & 65 & 97 \\
\hline$\geq 20$ & 69 & 97 & 53 & 89 & 75 & 99 \\
\hline
\end{tabular}

*Includes visits for bronchitis. COPD Chronic obstructive pulmonary disease

visits, patients with COPD were less likely to have spirometry than were those with asthma $(\mathrm{P}<0.0001)$, and they were substantially less likely to receive drugs $(\mathrm{P}<0.0001)$. Patients with both COPD and asthma were most likely to have spirometry, and, except for those with two to three visits, were as likely to receive drugs as were patients with asthma.

The patterns of prescription of inhaled drugs for asthma and COPD are shown in Figure 2. Patients with asthma received inhaled beta-agonists and steroids; of those with five physician visits, $78 \%$ had been prescribed the former and $65 \%$ the latter. They received ipratropium bromide considerably less often, with prescription rates exceeding $20 \%$ only in those with more than 19 visits. Approximately 20\% of asthmatics with three visits were not prescribed drugs. In patients with COPD, beta-agonists and steroids were less commonly prescribed than in patients with asthma $(\mathrm{P}<0.001)$, while ipratropium bromide was prescribed more often $(\mathrm{P}<0.0001)$. Over $40 \%$ of COPD patients with five physician visits were not prescribed drugs. Patients labelled with both asthma and COPD had patterns of beta-agonist and corticosteroid prescriptions that were similar to patients with asthma, and patterns of ipratropium bromide prescription that were similar to patients with COPD (Figure 2). Leukotriene antagonists and theophyllines (data not shown) were less commonly prescribed than inhaled drugs. Leukotriene antagonists were not commonly prescribed in COPD, and were prescribed for more than $20 \%$ of asthmatics who had more than 20 visits. Theophylline prescription patterns were roughly similar among the three diagnostic groups; these drugs were given to fewer than one-half of patients with over 20 visits. 


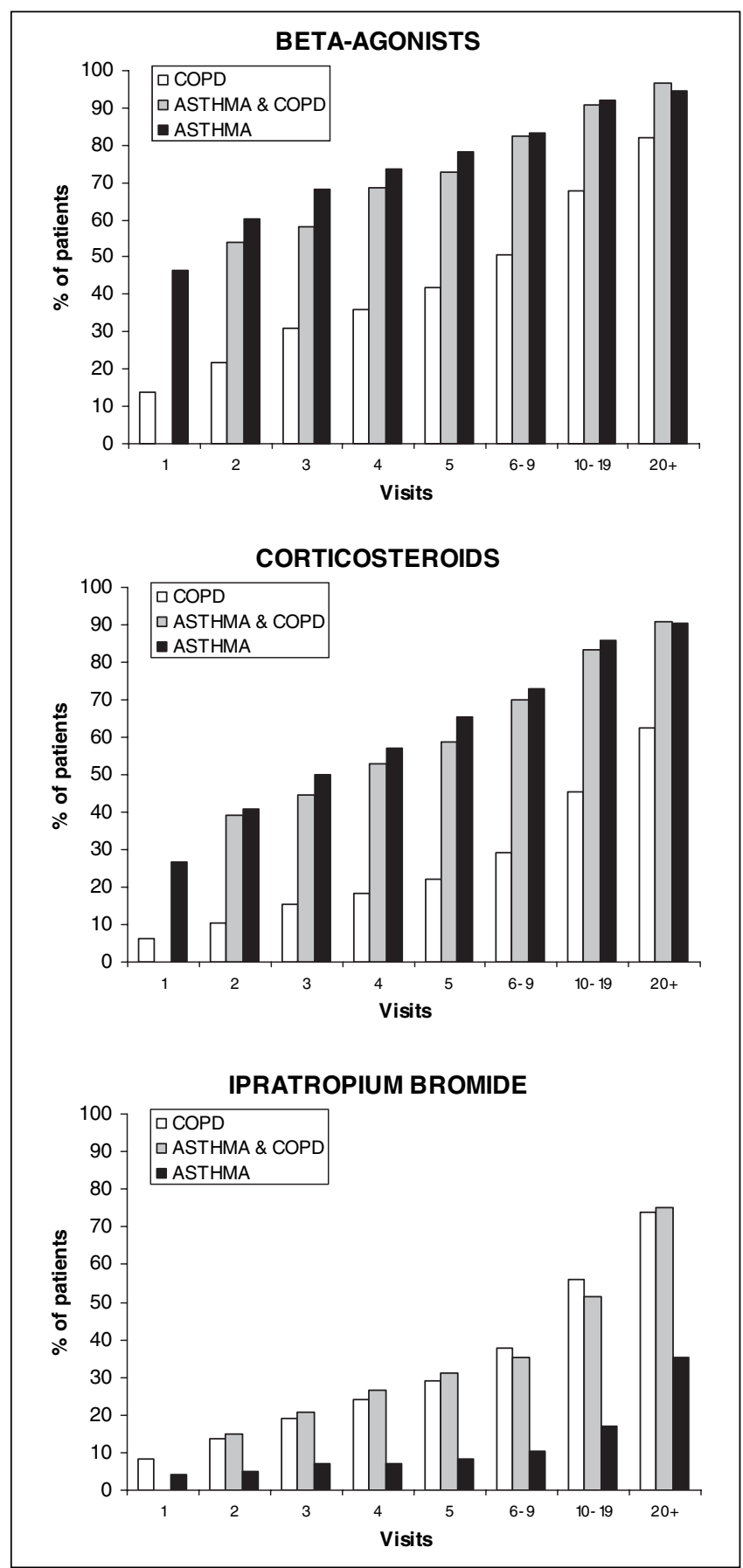

Figure 2) Percentages of patients receiving at least one prescription for inhaled drugs as a function of the number of physician visits. COPD Chronic obstructive pulmonary disease

Figure 3 illustrates the association between spirometry and drug prescription by showing the percentage of patients who were not prescribed any of the drugs examined as a function of whether they had spirometry. In patients with asthma, prescription rates were higher in patients who had spirometry than in those who did not. Although significant $(\mathrm{P}<0.001)$, this difference was not large, averaging approximately $3.7 \%$ (Figure 3 ), and was mostly due to higher prescription rates for inhaled steroids in asthmatics who had spirometry (data not shown). In patients labelled with both asthma and COPD, spirometry had a similar effect on drug prescriptions as in patients with

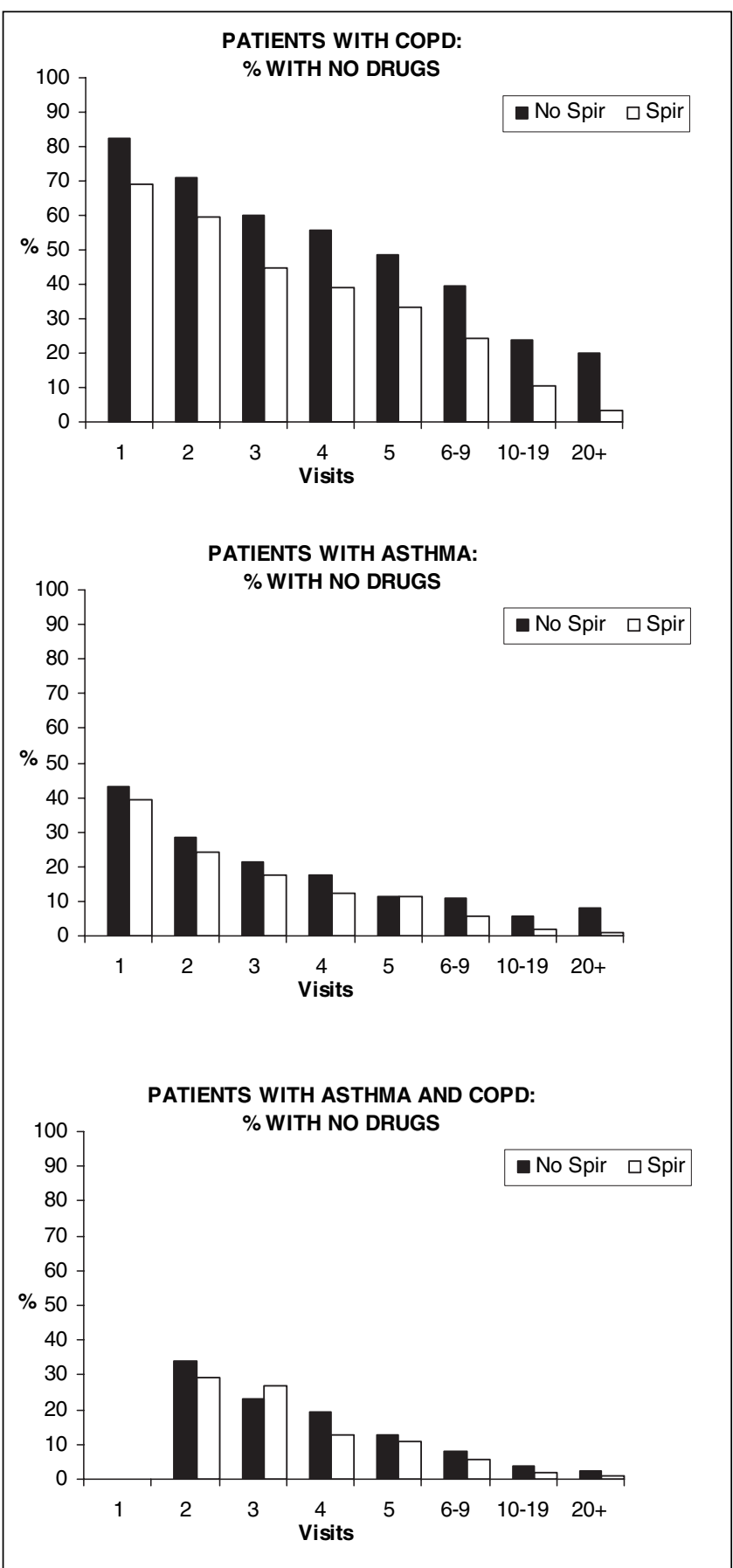

Figure 3) Percentage of people who did not receive any respiratory drugs as a function of the number of physician visits according to whether they underwent spirometry (Spir). COPD Chronic obstructive pulmonary disease

asthma, except that in the combination group, ipratropium bromide prescription rates were greater in those who had spirometry. In patients with COPD, drug prescription differences $(P<0.001)$ between those who had and did not have spirometry were, on average, $14.6 \%$ (Figure 3 ), and applied to the use of beta-agonists, corticosteroids and ipratropium bromide. As in the other groups, the prescription of theophylline was not related to spirometry.

Among patients with asthma, $18.7 \%$ received only one prescription compared with $21.3 \%$ for those with COPD and $4.9 \%$ for those with COPD and asthma. 
Patterns of drug use for patients who received prescriptions on more than one occasion are shown in Table 3. Patterns differed by diagnostic category: the coverage and the treatment period were shorter for patients with COPD than for the other two groups. Fifty per cent of patients with asthma discontinued their medication more than 85 days (median) before the end of coverage, and prescription rates were consonant with $30.9 \%$ of the recommended drug use (\% full dose). In patients with COPD, the interval between the date when the prescription ran out and the end of the coverage (median 26 days) was significantly shorter than for asthma patients $(\mathrm{P}<0.001)$. Drug supply in COPD accounted for $54 \%$ of the days that patients were presumably taking drugs. Patients with both diagnoses seldom discontinued drugs before the end of observation (median 1 day), and drug supply accounted for $56.4 \%$ of the days on drugs. Using the same analytical framework, the prescription of beta-agonists and inhaled steroids was examined in these patients; no difference was found between the patterns of use of the two drug classes in any of the diagnostic categories, and for both drug classes, the results were similar to the overall usage of respiratory drugs cited above.

\section{DISCUSSION}

We believe that we studied essentially all patients with the diagnoses of interest who had spirometry (1) or had been prescribed respiratory drugs. The drug database has been validated, and we did not access the data from the first year (1995) that they were available, avoiding any growing pains associated with establishing the database.

We initially examined data for people seen for bronchitis, COPD and asthma; however, the data from patients with bronchitis only are not presented because they showed fewer physician visits, and less spirometry and drug exposure than did the other groups. Over one-half of the patients with asthma and COPD were also seen for bronchitis, perhaps indicating an exacerbation of the underlying disease, and these visits for bronchitis were included in our assessments of asthma and COPD.

We interpret the distribution of the number of physician visits to reflect, among other things, the severity of illness. Patients who were labelled with both asthma and COPD were probably sicker than those with either label alone because that visit frequency was considerably greater (Table 1) and associated with increased numbers of patients with many visits, more of whom received spirometry and drug prescription.

Patients with COPD were less likely to have spirometry or receive drugs than were patients with asthma or asthma plus COPD. We noted this trend for spirometry previously (1), when the Manitoba Health data from 1991 to 1998 was examined, and were puzzled by it because the test is better for diagnosing COPD than asthma. Differences between COPD and the other two diagnostic groups were even larger for drug prescription (Table 2, Figure 3). This was the case for people with both few and many physician visits: approximately $30 \%$ of patients with COPD with six to nine visits received no respiratory drugs, while this was true for less than $10 \%$ of patients with asthma (Figure 3) or both asthma and COPD who had a similar number of physician contacts. There are two possible explanations for this. First, it is possible that physicians regarded many COPD patients as untreatable irrespective of disease severity, despite the numerous guidelines that recommend otherwise. Second, it is possible that COPD is a diagnosis that is used in an indiscriminate fashion, including
TABLE 3

Drug use in patients prescribed drugs on more than one occasion*

\begin{tabular}{lcccc}
\hline & Coverage $^{\dagger}$ & Treatment $^{\ddagger}$ & \% Full dose $^{\S}$ & DC drug $^{\text {T }}$ \\
\hline Asthma & 1532 & 1151 & 30.9 & 85 \\
& $(1006,1760)$ & $(497,1666)$ & $(14.2,63.6)$ & $(0,396)$ \\
COPD & 1066 & 770 & 54.0 & 26 \\
& $(564,1607)$ & $(287,1403)$ & $(23.2,86.2)$ & $(0,264)$ \\
Asthma + COPD & 1648 & 1300 & 56.4 & 1 \\
& $(1120,1792)$ & $(880,1772)$ & $(26.5,84.4)$ & $(0,120)$ \\
\hline
\end{tabular}

${ }^{*}$ All data are given as median (25th, 75 th percentiles); ${ }^{\dagger}$ Days between the first prescription and the end of observation; $¥$ Days between the first prescription and lapse of the last prescription; \$Fraction of days that the full dose prescribed was taken; "Days after the last prescription ran out that the patient had coverage. COPD Chronic obstructive pulmonary disease; DC Discontinued

individuals who are not thought to have serious disease and, therefore, do not merit spirometry or therapy. Both explanations may be true to some extent. People might be given the diagnosis of COPD in the absence of compelling symptoms, and when symptoms are present, there may be a tendency to label the patient with asthma. This would be a happier state of affairs than people with serious COPD not being treated, but it is possible that this also occurs, particularly when spirometry is not used to assess disease severity. It should be noted that our data are in general agreement with recently reported results from a telephone survey of patients with COPD (8) showing apparent underuse of spirometry and respiratory drugs.

Patients who underwent spirometry were more likely to receive drugs than those who did not (Figure 3). This was more notable in patients with COPD than in those with asthma. Spirometry was also associated with an increase in the percentage of patients with many physician contacts, but this influence was not notably greater in patients with COPD than in those with asthma or in those with COPD and asthma. The effect of spirometry in influencing visit distribution was less than the effect of drugs for all three diagnostic groups. Spirometry was associated with drug prescription and severity assessment, as indicated by visit distribution, but the effect was not striking.

Patterns of drug prescription differed between patients with COPD and asthma in ways that were predictable (Figure 2). People with asthma were commonly given betaagonists and inhaled steroids, and less commonly given ipratropium bromide, while patients with COPD were prescribed ipratropium bromide more often, and beta-agonists and steroids less often. Patients with both COPD and asthma received beta-agonists and inhaled steroids as often as those with asthma, and ipratropium bromide as often as those with COPD - another indication that physicians regarded these people as being more ill. Theophylline use was generally similar in all three diagnostic groups, in that its prescription was uncommon in people with fewer than 20 physician visits. Leukotriene antagonists were more commonly prescribed for patients with asthma than for the other two groups. It should be noted that leukotriene antagonists became widely available during the time period that was examined, indicating that their use was changing and probably did not reach stable, mature values. It should also be noted that these analyses assessed only the presence or absence of a single drug prescription and not long-term therapy (see below). It seemed that the 
diagnosis of asthma attracted the use of respiratory drugs. For the same number of physician visits, patients with asthma were as likely to receive drugs as those with both asthma and COPD as a diagnosis, and distinctly more likely to receive drugs than COPD patients.

Patterns of drug use were examined in patients with the diagnoses of interest who were given drugs on more than one occasion. In patients with asthma, drug use was compatible with intermittent, mild disease: drug use accounted for only $30.9 \%$ of the expected treatment period. In patients with COPD and those with COPD and asthma, there was a considerably greater tendency to renew prescriptions once started than there was among patients with asthma. Although drug quantities prescribed corresponded better with refill rates, the latter amounted to approximately $55 \%$ of the quantities prescribed. We thought that this low figure might be due to the ad hoc (according to need) use of bronchodilators, but found the same patterns of drug use for beta-agonists and inhaled corticosteroids, and the latter are usually prescribed on a fixed dosage schedule.

Our figures for drug use in people with asthma and COPD are not greatly different from those in the literature. Most studies examining compliance with prescribed medication have been performed in asthmatics, and have involved relatively few patients who were often involved in clinical trials $(9-12)$. Compliance rates (variously defined as the use of $50 \%$ to $70 \%$ of the prescribed medication) varied from 30\% to 63\%. Kelloway et al (13) did a study comparable to the present study in that it

\section{REFERENCES}

1. Anthonisen NR, Dik N, Manfreda J, Roos LL. Spirometry and obstructive lung disease in Manitoba. Can Respir J 2001;8:421-6.

2. American Thoracic Society. Standards for the diagnosis and care of patients with chronic obstructive lung disease. Am J Respir Crit Care Med 1995;152:S77-121.

3. Canadian Respiratory Review Panel. Guidelines for the Treatment of Chronic Obstructive Pulmonary Disease (COPD). Toronto: Medication Use Management Services Inc, 1998.

4. Pauwels RA, Buist AS, Calverley PM, Jenkins CR, Hurd SS; GOLD Scientific Committee. Global strategy for the diagnosis, management and prevention of chronic obstructive pulmonary disease. NHLBI/WHO Global Initiative for Chronic Obstructive Lung Disease (GOLD) Workshop summary. Am J Respir Crit Care Med 2001;163:1256-76.

5. Kozyrskyj AL, Mustard CA. Validation of an electronic, populationbased prescription database. Ann Pharmacother 1998;32:1152-7.

6. Internation Classification of Diseases, 9th Revision, Clinical Modification. Toronto: McGraw-Hill Inc, 1995:115-21.

7. Woodward M. Epidemiology:. Study Design and Data Analysis. Boca Raton: Chapman \& Hall/CRC, 1999.

8. Rennard S, Decramer M, Calverly PM, et al. Impact of COPD in North America and Europe in 2000: Subjects' perspective of Confronting COPD International Survey. Eur Respir J 2002;20:799-805.

9. Spector SL, Kinsman R, Mawhinney H, et al. Compliance of patients with asthma with experimental aerosolized medication: Implications for controlled clinical trials. J Allergy Clin Immunol $1986 ; 77: 65-70$. was derived from a database and compared pharmacy claims with prescribed amounts. In an upper middle class population who had already been on therapy for six months, the authors found a refill rate compatible with $57 \%$ of the prescribed doses of inhaled steroids. There are few examinations of medication compliance in patients with COPD. In the Lung Health Study $(14,15)$, a trial involving participants who were largely asymptomatic, inhaler compliance with two-thirds the prescribed dose was approximately 50\%. Self-reported underuse of drugs was documented in 54\% of symptomatic patients with COPD (16), and a recent database study from Quebec (17) showed equally poor compliance with inhaled steroids. Thus, our findings of refill rates compatible with $30 \%$ to $60 \%$ of the prescribed dose levels in an unselected population are not surprising.

\section{CONCLUSIONS}

The most striking finding of the present study was the apparent inconsistency of the assessment and treatment of COPD compared with asthma. The latter was associated with considerably higher rates of spirometry and drug use than was the former, and it appears that COPD is managed badly, the diagnosis is often made inappropriately or both. Perhaps appropriately, the availability of spirometry appeared to influence drug prescription more in COPD than in asthma. Finally, patterns of drug use were compatible with asthma being a more intermittent disease than the other diagnoses considered, but drug use appeared to account for only $31 \%$ to $56 \%$ of the drugs prescribed.

10. Mawhinney H, Spector SL, Kinsman RA, et al. Compliance in clinical trials of two nonbronchodilator, antiasthma medications. Ann Allergy 1991;66:294-9.

11. Dekker, Dieleman FE, Kaptein AA, Mulder JD. Compliance with pulmonary medication in general practice. Eur Respir J 1993;6:886-90.

12. Apter AJ, Reisine ST, Affleck G, Barrows E, ZuWallack RL. Adherence with twice-daily dosing of inhaled steroids. Socioeconomic and health-belief differences. Am J Respir Crit Care Med 1998;157:1810-7.

13. Kelloway JS, Wyatt RA, Adlis SA. Comparison of patients' compliance with prescribed oral and inhaled asthma medications. Arch Intern Med 1994;154:1349-52.

14. Rand CS, Nides M, Cowles MK, Wise RA, Connett J, for the Lung Health Study Research Group. Long-term metered-dose inhaler adherence in a clinical trial. Am J Respir Crit Care Med 1995;152:580-8.

15. Anthonisen NR, Connett JE, Kiley JP, et al, for the Lung Health Study. Effects of smoking intervention and the use of an inhaled anticholinergic bronchodilator on the rate of decline of $\mathrm{FEV}_{1}$. JAMA 1994;272:1497-505.

16. Dolce JJ, Crisp C, Manzella B, Richards JM, Hardin J, Bailey WC. Medication adherence patterns in chronic obstructive pulmonary disease. Chest 1991;99:837-41.

17. Blais L, Bourbeau J, Sheehy O, LeLorier J. Inhaled corticosteroids in COPD: Determinants of use and trends in patient persistence with treatment. Can Respir J 2004;11:27-32. 


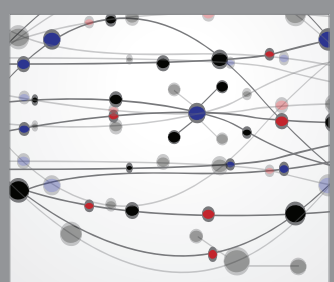

The Scientific World Journal
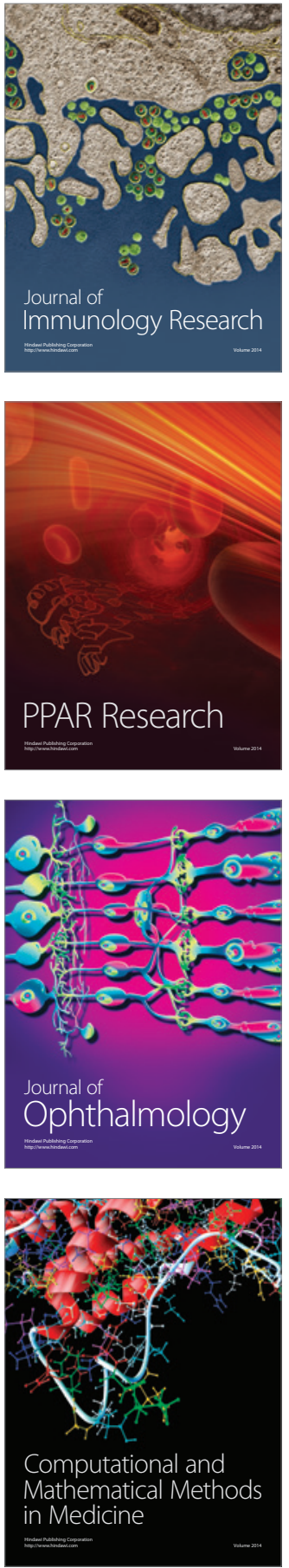

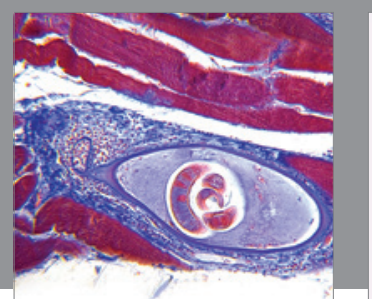

Gastroenterology Research and Practice

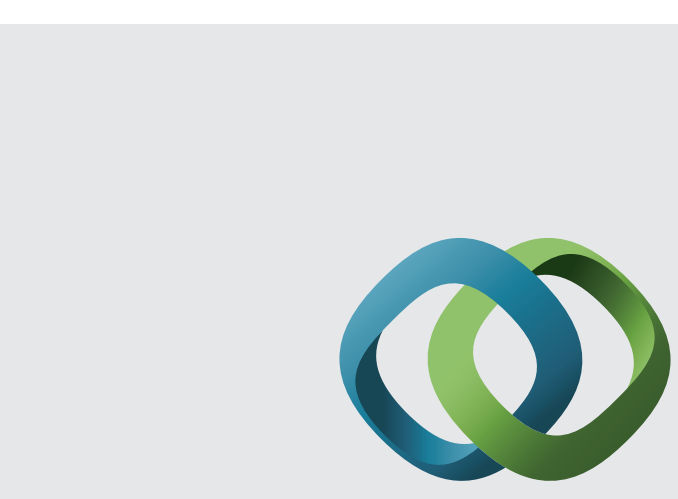

\section{Hindawi}

Submit your manuscripts at

http://www.hindawi.com
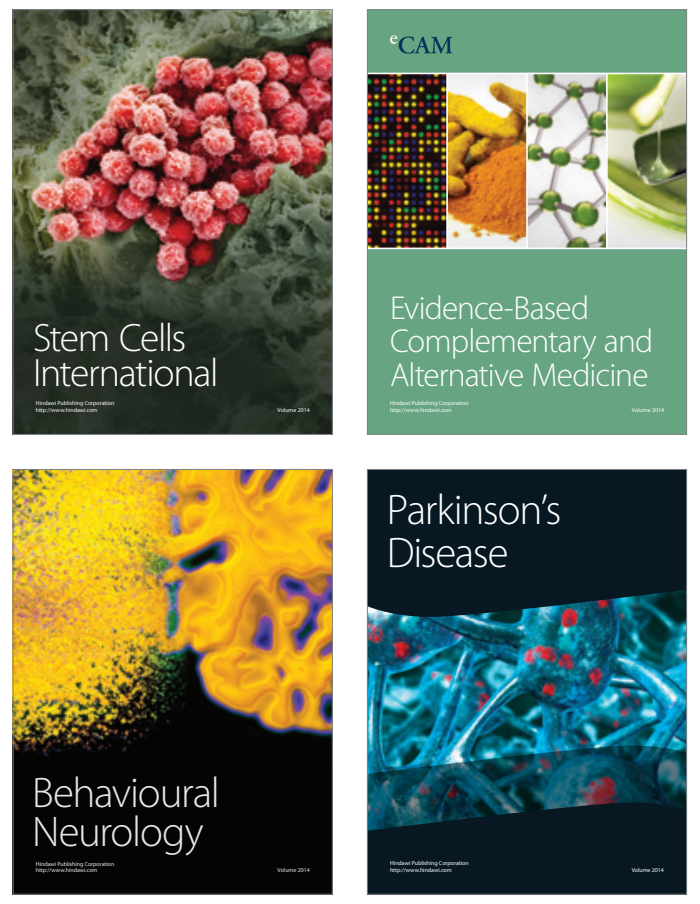
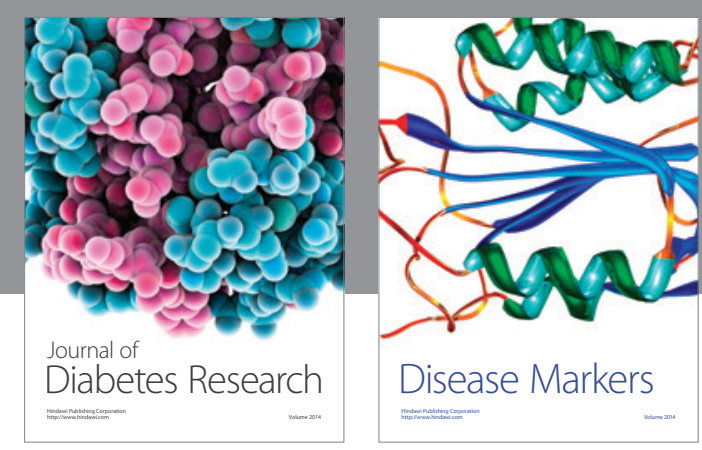

Disease Markers
